\title{
Modification of stage II procedure after hybrid palliation (bilateral pulmonary artery banding and ductal stenting) for hypoplastic left-sided heart syndrome: Modified arch reconstruction with retained stented ductus patch
}

Christopher A. Caldarone, MD, Osami Honjo, MD, Lee N. Benson, MD, and Glen S. Van Arsdell, MD, Toronto, Ontario, Canada

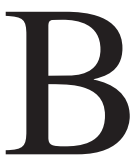
ilateral pulmonary artery banding and ductal stenting can be used as a "hybrid" alternative to Norwoodbased management for the palliation of neonates with single ventricle physiology. ${ }^{1}$ By using the hybrid strategy, first-stage palliation defers cardiopulmonary bypass and arch reconstruction to a second-stage procedure at 4 to 6 months of age. At the second stage, distal aortic arch reconstruction is more difficult than a neonatal Norwood reconstruction because the ductal stent often extends into the descending aorta.

The requirement for resection of all ductal tissue is based on observations that ductus tissue is friable, does not suture well, and

From The Hospital for Sick Children, Toronto, Ontario, Canada.

Received for publication Aug 3, 2007; accepted for publication Aug 14, 2007.

Address for reprints: Christopher Caldarone, MD, Division of Cardiovascular Surgery, The Hospital for Sick Children, 555 University Avenue, Toronto, Ontario M5G 1X8 (E-mail: christopher.caldarone@ sickkids.ca).

J Thorac Cardiovasc Surg 2007;134:1588-9

$0022-5223 / \$ 32.00$

Copyright $\odot 2007$ by The American Association for Thoracic Surgery doi:10.1016/j.jtcvs.2007.08.033 will contract after cessation of prostaglandins. After 4 to 6 months, however, stented ductal tissue is robust and handles sutures well. Consequently, the necessity of removing all stented ductal tissue can be questioned.

This report describes a simplified hybrid second-stage procedure that uses stented ductal tissue to reconstruct the aortic arch.

\section{Clinical Summary}

A neonate with hypoplastic left-sided heart syndrome underwent uneventful initial hybrid palliation and was discharged. At 6 months of age, he underwent a second-stage procedure. Parental consent and ethical approval from the Hospital for Sick Children Ethics Boardapproved Surgical Innovation Program were obtained.

Cardiopulmonary bypass was initiated, the branch pulmonary arteries were occluded, the patient was cooled, and circulatory and cardioplegic arrest was initiated. The main pulmonary artery was transected, and the origin of the branch pulmonary arteries was resected as a single large button (Figure $1, A-C$ ). The area of apposition between the ascending aorta and the stented ductus was then divided to the orifice of the aortic isthmus (Figure 1, D). Regional cerebral perfusion was initiated with inominate cannulation.

All stent material along the posterior aspect of the proximal descending aorta was resected (Figure 1,E). The remaining por-
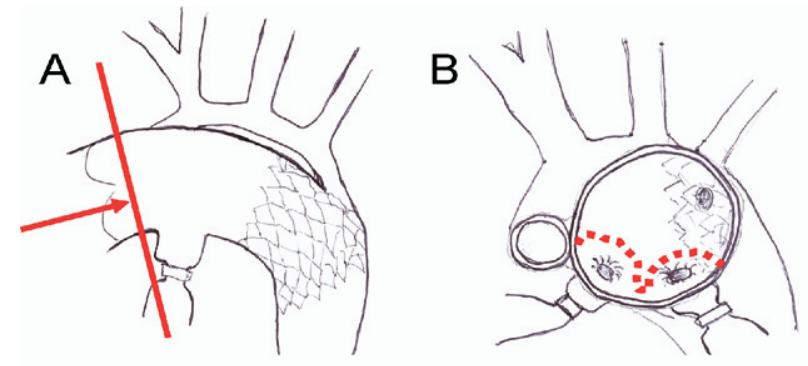

C
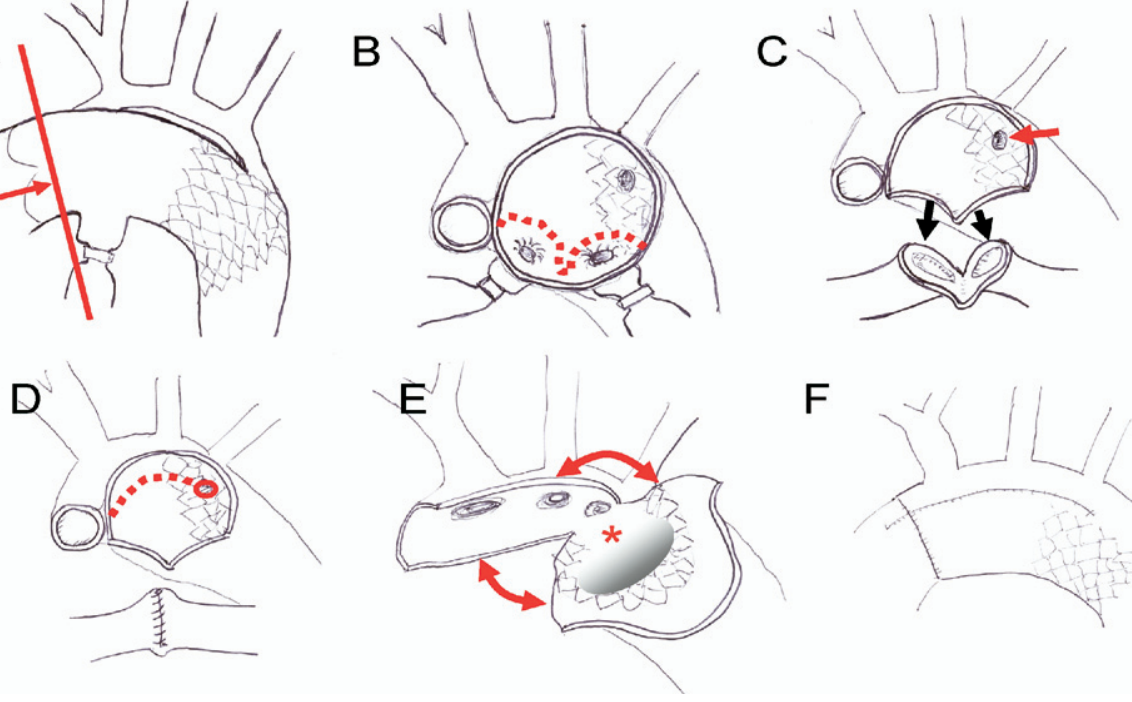

Figure 1. A, Left lateral view of the main pulmonary artery, ductus, aorta, and banded left pulmonary artery. The arrow indicates the orientation of subsequent views after division of the main pulmonary artery and aorta (red line). B, Resection of a single button incorporating the branch pulmonary arteries (dotted line). C, Orifice of the aortic isthmus (red arrow). D, Incision site is marked. E, Remaining stent on the posterior wall of the aorta is resected $\left.{ }^{*}\right)$, and the lateral free edges are reapproximated (arrows). F, After side-to-side approximation of the ascending aorta and main pulmonary artery, continuity with the reconstructed aorta is established. 
tion of stented ductus was used as a "patch" for arch reconstruction. The arch was reconstructed by sewing the lateral free edges of the divided ductus to the divided native aortic arch. Continuity was then restored with the main pulmonary artery and proximal aorta (Figure 1, F).

The branch pulmonary artery bands were removed, and the branches were dilated. Continuity was restored by folding the pulmonary artery button and sewing the anterior free edges together. A bidirectional cavopulmonary shunt was constructed. The patient's postoperative course was unremarkable, and he was discharged on postoperative day 9. After 1 month, the postoperative echocardiogram demonstrated an unobstructed reconstructed aortic arch.

\section{Discussion}

The use of retained stented ductal material to reconstruct the aortic arch offers several advantages over traditional homograft reconstruction.

1. The stented material is "preformed" to fit the contour of the transverse aortic arch.

2. Continuity between the ductal material and the descending aorta avoids the need for exposure of this area, obviates any distal sewn anastomoses. and thereby prevents bleeding and reduces potential for recurrent laryngeal nerve injury.
3. Avoidance of homograft material may improve the potential for future transplantation. ${ }^{2}$

Potential disadvantages include the following:

1. There is potential for aneurysmal ductal dilation. The retention of the stent deeply embedded in the tissue, however, leaves the tissue "wire-reinforced," and this risk seems small.

2. Any circumferential retention of stent material will likely require reoperation for coarctation; consequently, meticulous removal of the stent in the posterior aorta is important.

3. The growth potential of the isthmus area after stent removal is not known.

The use of retained stented ductal material facilitates the hybrid second-stage procedure and thereby improves the relative merit of the hybrid management strategy in comparison with the Norwood strategy. Long-term follow-up will be required.

\section{References}

1. Akintuerk H, Michel-Behnke I, Valeske K, et al. Stenting of the arterial duct and banding of the pulmonary arteries: basis for combined Norwood stage I and II repair in hypoplastic left heart. Circulation. 2002; 105:1099-103.

2. Meyera SR, Campbell PM, Rutledge JM, et al. Use of an allograft patch in repair of hypoplastic left heart syndrome may complicate future transplantation. Eur J Cardiothorac Surg. 2005;27:554-60.

\title{
Right minithoracotomy as an alternative approach for endovascular repair of thoracic aortic aneurysm
}

\author{
Igor Vendramin, MD, ${ }^{a}$ Gianluca Piccoli, MD, ${ }^{\text {b }}$ Daniele Gasparini, MD, ${ }^{\mathrm{b}}$ and Ugolino Livi, MD, ${ }^{a}$ Udine, Italy
}

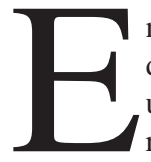

ndovascular repair of chronic descending thoracic aortic diseases (aneurysm and dissection) is now a widely used treatment with satisfactory short- and midterm results in terms of morbidity and mortality. ${ }^{1,2}$ Nevertheless, absence of available traditional access (femoral artery, iliac artery, right subclavian artery) remains a great challenge for

From the Division of Cardiothoracic Surgery, Department of Cardiopulmonary Sciences, ${ }^{\mathrm{a}}$ and the Division of Vascular and Interventional Radiology, Department of Radiologic Sciences, ${ }^{\mathrm{b}}$ University of Udine Medical School, Udine, Italy.

Received for publication June 8, 2007; accepted for publication June 22, 2007.

Address for reprints: Igor Vendramin, MD, Division of Cardiothoracic Surgery, Department of Cardiopulmonary Sciences, Piazzale Santa Maria della Misericordia, Udine 33100, Italy (E-mail: Igor.vendramin@ virgilio.it).

J Thorac Cardiovasc Surg 2007;134:1589-91

$0022-5223 / \$ 32.00$

Copyright $\odot 2007$ by The American Association for Thoracic Surgery doi:10.1016/j.jtcvs.2007.06.038 physicians who have to explore new strategies to avoid major surgical approaches.

We report the case of a thoracoabdominal aortic aneurysm treated with stent grafts implanted through the ascending aorta with a right anterior minithoracotomy approach.

\section{Clinical Summary}

A 59-year-old man had a thoracoabdominal aneurysm and severe atherosclerotic disease of the femoral and iliac arteries and brachiocephalic trunk, causing severe and obstructive stenoses. The abdominal aorta was not available because of the aneurysmatic disease nor was the right subclavian artery owing to kinking. Preoperative imaging (computed tomographic [CT] scan) demonstrated an aneurysm involving the descending aorta between the left subclavian artery (LSA) and the celiac trunk (Figure 1, A) and a second subrenal abdominal aortic aneurysm.

The procedure was performed with the patient under general anesthesia with double-lumen intubation, and guidance was provided by transesophageal echocardiography and fluoroscopy. A 7.0-cm incision was made at the level of the second right anterior intercostal space (Figure 2), and the right internal thoracic artery was dissected and cut. A small rib retractor was used to open the pericardium, and a side-biting clamp was introduced to partially 